\title{
Newly developed microsatellite markers for the Eurasian Sparrowhawk, Accipiter nisus (Linnaeus, 1758), with a prelimi- nary assessment of its genetic variation
}

\author{
Jannik Scherer', Michael Wink², Uwe Schröder ${ }^{3}$ \& Miguel Vences ${ }^{*}$ \\ ${ }^{1}$ Zoological Institute, Technische Universität Braunschweig, Mendelssohnstr. 4, 38106 Braunschweig, Germany \\ ${ }^{2}$ Institut für Pharmazie und Molekulare Biotechnologie (IPMB), Abt. Biologie, Universität Heidelberg, Im Neuen- \\ heimer Feld 364, 69120 Heidelberg, Germany \\ ${ }^{3}$ Institute of Environmental and Sustainable Chemistry, Technische Universität Braunschweig, Hagenring 30, 38106 \\ Braunschweig, Germany \\ Corresponding author, e-mail: m.vences@tu-braunschweig.de - ORCID: 0000-0003-0747-0817
}

\begin{abstract}
We report on the development of a set of microsatellite markers for the Eurasian Sparrowhawk, Accipiter nisus (Linnaeus, 1758), using an enrichment / high-throughput sequencing approach. Out of 9328 potential microsatellites identified, we established 24 tetrameric markers and assessed allelic variation based on samples from continental Europe and the Macaronesian archipelagos. Along with sequences of the mitochondrial cox 1 gene from across the species' range, we use the new markers for a preliminary assessment of genetic variation of $A$. nisus. We find a low mitochondrial variation with only four coxl haplotypes, one of which present in all five subspecies studied. Microsatellite analyses suggested a single, panmictic population, with a very low indication for differentiation between the European A. nisus nisus and the Macaronesian $A$. nisus granti. However, given the relatively few samples included in this study, our results require confirmation from more in-depth analyses with comprehensive sampling. The newly established microsatellites provide a tool for conservation assessments, conservation breeding and paternity analysis in this widespread raptor.
\end{abstract}

KEY WORDS Aves; Accipitridae; microsatellite genotyping; DNA barcoding; subspecies; phylogeography.

Received 28.10.2020; accepted 04.05.2021; published online 03.06.2021

\section{INTRODUCTION}

The Eurasian Sparrowhawk, Accipiter nisus (Linnaeus, 1758), is a rather small bird of prey characterized by distinct sexual dimorphism in size and coloration (Mebs, 2002), and a barred pattern on feathers of chest and belly as typical for species in the genus Accipiter Brisson, 1760 (Ortlieb, 1987; Mebs, 2002). Sparrowhaks breed in most of Europe and across Asia to the Pacific coast, plus Northern Africa and Macaronesia (Or- tlieb, 1987; Mebs, 2002; Ferguson-Lees \& Christie, 2009).

In general, Accipiter nisus is considered to be polytypic, with six to nine subspecies usually accepted which differ from each other mostly in body size, details of coloration and distribution. Besides the nominal subspecies occurring from continental Europe to southwestern Siberia and Central Asia, this includes at least $A$. nisus granti from Macaronesia (including Madeira and the Canary Islands), A. nisus melaschistos from eastern 
Afghanistan to southwestern China, A. nisus nisosimilis from northwestern Siberia to northern China and Japan, and A. nisus wolterstorffi from Sardinia and Corsica, A. nisus punicus from northwestern Africa (Ortlieb, 1987; Gill et al., 2020), and in some taxonomic schemes also $A$. nisus dementjevi from Pamir-Alai to Tien Shan Mountains in Central Asia. Overall, the Eurasian Sparrowhawk is considered as Least Concern according to IUCN criteria (BirdLife International, 2016), but some subspecies are subject of particular conservation actions, e.g., the Macaronesian form $A$. nisus granti. Setting regional conservation priorities for this species requires understanding whether the currently distinguished subspecies represent genetically divergent management units. However, the genetic differentiation of the Eurasian Sparrowhawk remains poorly studied. Kerr et al. (2009), Johnsen et al. (2010), Breman et al. (2013), Aliabadian et al. (2013) and Saitoh et al. (2015) together provided a total of 36 DNA barcodes, i.e., partial DNA sequences of the mitochondrial gene for cytochrome oxidase subunit I ( $\operatorname{cox} 1)$, for $A$. nisus specimens from various sites across its range, revealing only very limited differences. No highly variable nuclear-encoded molecular markers, such as microsatellites, have been specifically developed for this species, although markers exist for related species such as the Northern Goshawk, Accipiter gentilis (developed by Topinka \& May, 2004), and the phylogeographic structure of the Eurasian Sparrowhawk has not yet been studied from the perspective of the nuclear genome.

As a basis for such studies, we here present 24 newly developed microsatellite markers for the Eurasian Sparrowhawk, and test these in a preliminary assessment of genetic differentiation in the species, along with an additional 26 cox 1 barcode sequences.

\section{MATERIAL AND METHODS}

We extracted genomic DNA from muscle tissue samples of four specimens of $A$. nisus from Tenerife, Germany, Finland and Georgia (Table 1) and sent the pooled DNA to the Sequencing Genotyping Facility, Cornell Life Sciences Core Laboratory Center (CLC), U.S.A., for development of a mi- crosatellite library. Digestion of DNA took place in three separate reactions with the restriction enzymes AluI, RsaI, and Hpy166II, and products were combined in equal amounts after heat inactivation of the restriction enzymes. The blunt ends were adenylated $(+\mathrm{A})$ with Klenow (exo) and dATP, and after heat inactivation of the Klenow (exo-), the reactions were supplemented with ATP to $1 \mathrm{mM}$ and an Illumina Y-adaptor was ligated with T4 DNA ligase. Enrichment of the fragments for microsatellites took place by hybridisation to and magnetic capture of biotinylated repeat probes (representing two unique dimers, five unique trimers, seven unique tetramers and two unique pentamers), followed by amplification and barcoding by PCR, and sequencing on an Illumina MiSeq instrument $(2 \times 250$ bp paired reads $)$. SeqMan NGen (version 11) was used for raw read assembly, and the program msatcommander 1.0.8 beta (for Mac OSX) was employed to scan the assembly for microsatellite loci and automatically design primer pairs. The constructed library contained 9328 proposed microsatellite markers with minimum consecutive perfect repeat lengths of at least six (12 bp) for any dimer and at least five for any trimer, tetramer, or pentamer and PCR product size of $150-450 \mathrm{bp}$, and is available as supplementary information (Supplementary Table S1 and from Figshare under DOI 10.6084/m9.figshare.14604537. Out of this library, we chose 24 loci based on following criteria (Perl et al. 2018): (i) tetrameric, (ii) repeat motif between 10 and 15, (iii) less than 1000 reads, as deep coverage could indicate multiple copies and (iv) GC content of 50 (Table 2), and tested these loci for successful amplification and for yielding unambiguously scorable and polymorphic PCR products.

Microsatellites were amplified following the nested protocol of Schuelke (2000), modified to use rather than a M13 sequence the Illumina sequencing primer sequence (ACACTCTTTCCCTACACGACGCTCTTCCGATCT) as linker, i.e., this sequence preceded all forward primers and was included as a FAM-, NED- or HEX-labelled linker in the PCR. The amplification protocol consisted of 15 min of initial denaturation at $94^{\circ} \mathrm{C}, 30$ cycles of $94^{\circ} \mathrm{C}(30 \mathrm{~s}), 60^{\circ} \mathrm{C}(45 \mathrm{~s}), 72^{\circ} \mathrm{C}(45 \mathrm{~s})$, followed by 8 cycles of $94^{\circ} \mathrm{C}(30 \mathrm{~s}), 53^{\circ} \mathrm{C}(45 \mathrm{~s}), 72^{\circ} \mathrm{C}(45 \mathrm{~s})$, and a final elongation step of $10 \mathrm{~min}$ at $72^{\circ} \mathrm{C}$. PCR products were diluted once with $15 \mu$ l of RNase- 
free water, $15 \mu \mathrm{l}$ of Genescan 500-ROX size standard (Applied Biosystems) added to $1 \mu \mathrm{l}$ of each diluted product, and fragment analysis was performed on an ABI 3130xl Genetic Analyzer. Three markers of different product sizes and labelled with FAM, NED and HEX were combined in each run. We called alleles with GeneMapper ${ }^{\circledR}$ (SoftGenetics, State College, PA, U.S.A); ambiguous calls were either excluded if poor quality, or rounded up to the next unambiguous allele size. We tested for HardyWeinberg equilibrium and linkage disequilibrium in Arlequin (Excoffier et al., 2005) under Bonferroni correction (Rice, 1989).

We analysed population structure with the software STRUCTURE version 2.3.4 (Pritchard et al. 2000) under the assumption of an admixture model with correlated allele frequencies and locprior. We compared the number of clusters $(\mathrm{K})$ with 1 million Markov Chain Monte Carlo (MCMC) iterations and a burn-in of 100,000, repeating each assessment of $\mathrm{K}$ ten times. To assess the optimal number of clusters we followed the $\Delta \mathrm{K}$ method by Evanno et al. (2005) using STRUCTURE HARVESTER (Earl \& von Holdt 2012). Principal Component Analyses (PCA) of microsatellite allele data was carried out with the packages diveRsity v. 1.9.9 (Keenan et al. 2013) and adegenet v. 2.1.3 (Jombart 2008) in the $\mathrm{R}$ environment ( $\mathrm{R}$ Core Team 2020), following Jombart et al. (2009).

We sequenced the DNA barcode region of the mitochondrial gene for cytochrome oxidase subunit $1(\operatorname{cox} 1)$ with the primer pairs Vert-F1 and Vert-R1 (Ward et al., 2005), and dgLCO1490 and dgHCO2198 (Meyer et al., 2005), using standard PCR protocols. PCR products were sequenced on automated capillary sequencers at LGC Genomics (Berlin, Germany), sequences quality-checked in CodonCode Aligner (CodonCode Corporation), aligned and trimmed to equal length in MEGA7 (Kumar et al., 2016). All newly determined sequences were submitted to GenBank (accession numbers MZ208929-MZ208954. New sequences were aligned with sequences available from Genbank (Table 1), with a matrix of 586 bp kept for analysis. To reconstruct a haplotype network we first inferred a Maximum Likelihood tree with the JukesCantor substitution model in MEGA7 (Kumar et al., 2016), and used this tree together with the alignment as input for Haploviewer (written by G. B. Ewing; http: //www.cibiv.at/ greg/haploviewer), a software that implements the methodological approach of Salzburger et al. (2011).

\section{RESULTS}

The 32 samples available for microsatellite genotyping represented two $A$. nisus subspecies: the nominal subspecies $A$. nisus nisus from different parts of Europe, and A. nisus granti from Madeira and Tenerife (samples marked "New" in Table 1). We tested 24 microsatellite markers, all with tetranucleotide repeats (Table 2); two of these turned out to be monomorphic for the samples analyzed (An2789 and An14372) and were excluded from all subsequent analyses, but are reported here as they may become useful in a different context in future studies (e.g., Hailer et al., 2005; Nazareno \& dos Reis, 2011). The remaining 22 markers had between 2 and 10 alleles (average 4.5), with an allele size range (including primers and linker) between 166 and 414 nucleotides. In two markers (An1107 and An22524) the amount of missing data was high (43.8\% and $59.4 \%$ ); for the remaining markers, missing data ranged from $3.1-28.1 \%$ (Table 2). Amplification failure amounted to $20.0 \%$ on average, with three samples $>50 \%$ missing data, and the remaining samples having $0-45 \%$ (average $14.5 \%$ ) missing data.

Significant differences between expected and observed heterozygosity were found in four loci (An3169, An8617, An13004 and An23385) suggesting they may not be in Hardy-Weinberg equilibrium; however, in separate analyses for ad-hoc geographical groups (Macaronesia, Iberian Peninsula, Central Europe, Eastern Europe, Scandinavia), no significant differences between expected and observed heterozygosity were found for these and other markers. To explore the presence of possible genetic clusters in the data, we ran STRUCTURE with the allele matrix of all except the two monomorphic markers, alternatively using (i) subspecies assignment (granti and nisus) or (ii) ad-hoc geographical groups as locprior; and then repeated both analyses (iii-iv) after also excluding the markers with excessive missing data and potential deviation from Hardy Weinberg equilibrium. In all four analyses, the highest likelihood (and smallest standard deviation among replicate runs) was for $\mathrm{K}=1$, i.e., the assumption 


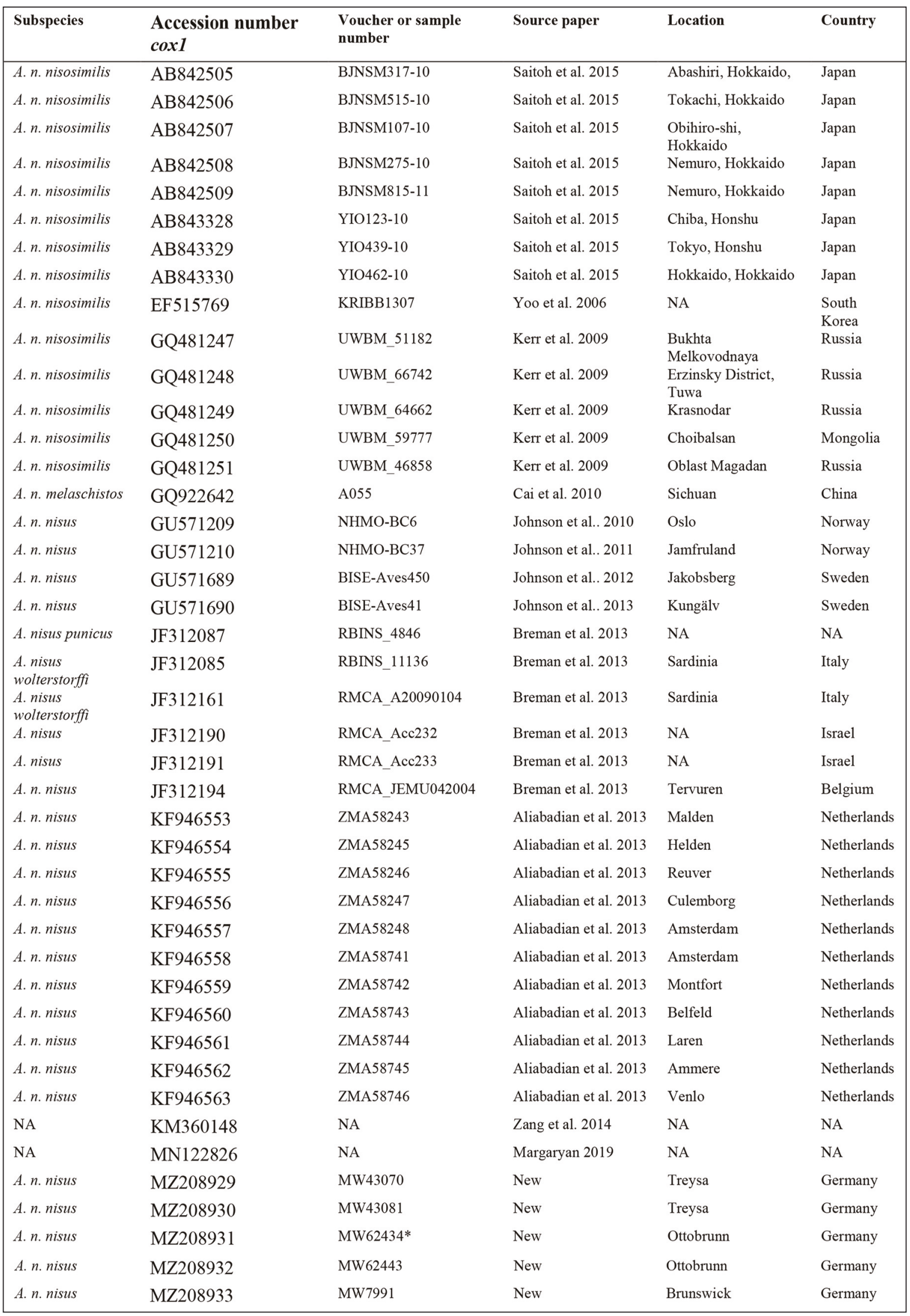




\begin{tabular}{|c|c|c|c|c|c|}
\hline A. n. nisus & MZ208934 & MW9891 & New & Westfalen & Germany \\
\hline A. n. nisus & MZ208935 & MW9897 & New & South Argyllshire & UK \\
\hline A. n. nisus & MZ208936 & MW9898 & New & South Argyllshire & UK \\
\hline A. n. nisus & MZ208937 & MW9899 & New & South Argyllshire & UK \\
\hline A. n. nisus & MZ208938 & MW7482 * & New & Hamina & Finland \\
\hline A. n. nisus & MZ208939 & MW7483 & New & Parikkala & Finland \\
\hline A.n. nisus & MZ208940 & MW7484 & New & Pälkäne & Finland \\
\hline A. n. nisus & MZ208941 & MW66072* & New & Batum & Georgia \\
\hline A. n. nisus & MZ208942 & MW66073 & New & Batum & Georgia \\
\hline A.n. nisus & MZ208943 & MW66074 & New & Batum & Georgia \\
\hline A. n. nisus & MZ208944 & MW2594 & New & Skaland & Norway \\
\hline A. n. nisus & MZ208945 & MW2620 & New & Bleikvasslia & Norway \\
\hline A. n. nisus & MZ208947 & MW2821 & New & Igis & Switzerland \\
\hline A.n.nisus & MZ208948 & MW2826 & New & Malans & Switzerland \\
\hline A. n. nisus & MZ208949 & MW59 & New & Bonaduz & Switzerland \\
\hline A. n. nisus & MZ208950 & MW9900 & New & NA & Switzerland \\
\hline A. n. nisus & MZ208951 & MW9901 & New & NA & Switzerland \\
\hline A. n. nisus & MZ208952 & MW21692 & New & Lleida & Spain \\
\hline A. n. nisus & NA & MW63905 & NA & Frielendorf & Germany \\
\hline A. n. nisus & NA & MW2588 & NA & Skaland & Norway \\
\hline A. n. nisus & NA & MW2589 & NA & Oksfjordhamn & Norway \\
\hline A. n. granti & MZ208946 & MW9893 & New & Madeira & Portugal \\
\hline A. n. granti & MZ208953 & MW19750* & New & Tenerife & Spain \\
\hline A. n. granti & MZ208954 & MW19753 & New & Tenerife & Spain \\
\hline A. n. granti & NA & MW19751 & NA & Tenerife & Spain \\
\hline A. n. granti & NA & MW19752 & NA & Tenerife & Spain \\
\hline A. n. granti & NA & MW19754 & NA & Tenerife & Spain \\
\hline
\end{tabular}

Table 1. DNA sequences of the cox1 gene used for haplotype network reconstruction, and additional samples used for microsatellite genotyping, with sample numbers, GenBank accession numbers (will be added upon manuscript acceptance for new samples) and locality information. Samples with MW numbers (tissue collection of Michael Wink) were newly sequenced for this study for cox 1 and genotyped for microsatellites. NA, information not available (samples with NA instead of accession number were not sequenced for cox1 but genotyped for microsatellites only). Asterisks mark the four samples that were used for microsatellite development.

of a single panmictic cluster (Figs. 1-4). The highest $\Delta \mathrm{K}$ corresponded to $\mathrm{K}=2$ in analyses (i) and (ii), and to $\mathrm{K}=4$ in analyses (iii) and (iv); this method however cannot assess $\mathrm{K}=1$. Plots of cluster assignment of individual samples provided no evidence for actual clusters: each individual had similar assignment probabilities to the two or four clusters specified, with perhaps a minimal tendency in some runs to differentiate the Macaronesian samples (subspecies granti) by slightly different cluster assignment probabilities (Figs. $1-8)$. PCAs of the microsatellite data, with the 22marker or 16-marker data sets, supported the results of the clustering analyses and revealed no apparent geographical or subspecific groupings.
Samples of $A$. nisus granti had their group centroid slightly shifted compared to those of $A$. nisus nisus, but both groups were widely overlapping along both axes of PC1 and PC2 (Figs. 5, 10).

Analysis of the altogether 64 cox 1 sequences of A. nisus from across its range which, based on location, represent six currently accepted subspecies, revealed a very low differentiation in this mitochondrial gene. After exclusion of the single sample of A. nisus. punicus (accession number JF312087) for which only a very short DNA fragment was available, four haplotypes were recognized in the $586 \mathrm{bp}$ alignment, differing from each other by a maximum of two mutational steps (Figs. $9,10)$. The central haplotype contained 44 samples 


\begin{tabular}{|c|c|c|c|c|c|c|c|c|}
\hline Marker & $\begin{array}{l}\text { Repeat } \\
\text { motif }\end{array}$ & Primer sequence (5'-3') & $\begin{array}{l}\text { N samples } \\
\text { genotyped }\end{array}$ & $\mathbf{N}$ alleles & $\begin{array}{l}\text { Allele } \\
\text { size range }\end{array}$ & HO & HE & $\begin{array}{l}\text { Missing } \\
\text { data }\end{array}$ \\
\hline An2789\# & (AAAC)6 & $\begin{array}{l}\text { Fwd: CTCTGCAAGCAAATCCCGTAG } \\
\text { Rev: CCAGTAACAAGGGCAAGGAAC }\end{array}$ & 24 & 1 & 347 & NA & NA & $25.0 \%$ \\
\hline An14372\# & $(\mathrm{AAAC}) 7$ & $\begin{array}{l}\text { Fwd: TAAAGAGATGGGAGCAGTTGG } \\
\text { Rev: GTGCAGGGTATGATCACTTTGG }\end{array}$ & 25 & 1 & 433 & NA & NA & $21.9 \%$ \\
\hline An22524\#\# & (AAAG) 11 & $\begin{array}{l}\text { Fwd: CACAGCACCATCACTCCTTTC } \\
\text { Rev: CGGAGGAACACATGCATACAG }\end{array}$ & 13 & 4 & $240-272$ & 0.385 & 0.351 & $59.4 \%$ \\
\hline An1107\#\# & $(\mathrm{AAAC}) 8$ & $\begin{array}{l}\text { Fwd: ACATGCTAACTCTGCTCCAG } \\
\text { Rev: AGTTACCCACGACTTGCAAAG }\end{array}$ & 18 & 2 & $348-364$ & 0.111 & 0.110 & $43.8 \%$ \\
\hline An13004\#\# & $(\mathrm{ACCT}) 6$ & $\begin{array}{l}\text { Fwd: TAGCCTGCTTTGTAAGTGGG } \\
\text { Rev: AAATTCGATCACAGGAGCCAC }\end{array}$ & 25 & 3 & $194-214$ & $0.320^{*}$ & 0.536 & $21.9 \%$ \\
\hline An377\#\# & $(\mathrm{ACTC}) 15$ & $\begin{array}{l}\text { Fwd: GTGACAGAGTGACTTGGCATG } \\
\text { Rev: AAGGATTCTGGAAGGTGGACC }\end{array}$ & 28 & 7 & $177-197$ & 0.793 & 0.759 & $9.4 \%$ \\
\hline An3169\#\# & $(\mathrm{ATCC}) 15$ & $\begin{array}{l}\text { Fwd: AGGACAACACATCTCCCAGTC } \\
\text { Rev: CCACACGTCTTTCCATCTGAC }\end{array}$ & 24 & 6 & $177-231$ & $0.542 *$ & 0.807 & $25.0 \%$ \\
\hline An8617\#\# & $(\mathrm{ATCC}) 7$ & $\begin{array}{l}\text { Fwd: TGAGGAGTCAGGTGAAAGAAGG } \\
\text { Rev: TGCCTTGAGATTCATGTGGAC }\end{array}$ & 26 & 4 & $197-209$ & $0.077^{*}$ & 0.281 & $18.8 \%$ \\
\hline An23385\#\# & $(\mathrm{ATCC}) 10$ & $\begin{array}{l}\text { Fwd: TTCAGGGATATGCTGGATGGG } \\
\text { Rev: CTCCTGTCCATCCATGTCAATG }\end{array}$ & 24 & 6 & $245-273$ & $0.667^{*}$ & 0.864 & $25.0 \%$ \\
\hline An2088 & $(\mathrm{AACC}) 7$ & $\begin{array}{l}\text { Fwd: ATAGGATGCAGAAGAGGACCC } \\
\text { Rev: GAGGTAAGGGACAGCTGAAATC }\end{array}$ & 26 & 8 & $241-273$ & 0.692 & 0.825 & $18.8 \%$ \\
\hline An2977 & $(\mathrm{ACAG}) 8$ & $\begin{array}{l}\text { Fwd: TACATTGGCCGAGATCTGCAG } \\
\text { Rev: CACAGTCAAGCATTTCCCTCC }\end{array}$ & 24 & 5 & $264-280$ & 0.417 & 0.480 & $25.0 \%$ \\
\hline An3053 & $(\mathrm{AAAC}) 8$ & $\begin{array}{l}\text { Fwd: ACCCTGATTGTAGCAGTAGTCC } \\
\text { Rev: AGACTGCATGGGATTCCTAGAC }\end{array}$ & 26 & 3 & $326-334$ & 0.346 & 0.298 & $18.8 \%$ \\
\hline An3611 & $(\mathrm{ATCC}) 7$ & $\begin{array}{l}\text { Fwd: GGACTTCAGCGGGTTATTCAC } \\
\text { Rev: AGCTATCTCCTGTCCATCCATG }\end{array}$ & 27 & 9 & $202-234$ & 0.815 & 0.861 & $15.6 \%$ \\
\hline An3738 & $(\mathrm{AAAC}) 9$ & $\begin{array}{l}\text { Fwd: CTGACCTACATGCTGCAACAC } \\
\text { Rev: CCAAACAGTCTAACCCACAACC }\end{array}$ & 31 & 4 & 171-191 & 0.786 & 0.766 & $12.5 \%$ \\
\hline An7105 & $(\mathrm{AAGG}) 12$ & $\begin{array}{l}\text { Fwd: AACTCCATTCCAACCAGACCC } \\
\text { Rev: CAATCCCTTTGTCTTCCTCCC }\end{array}$ & 26 & 10 & $203-251$ & 0.654 & 0.865 & $18.8 \%$ \\
\hline An17888 & $(\mathrm{AGCC}) 9$ & $\begin{array}{l}\text { Fwd: CTGCCATGTGAGAAGTGGAAC } \\
\text { Rev: ACTATGCCGTCTATTCCCACC }\end{array}$ & 29 & 2 & $172-180$ & 0.104 & 0.164 & $9.4 \%$ \\
\hline An18968 & $(\mathrm{AAAC}) 6$ & $\begin{array}{l}\text { Fwd: GCATCTGACCTCGTTTGTGTC } \\
\text { Rev: TCCTAATGAGACCTGAGCACC }\end{array}$ & 28 & 3 & $406-414$ & 0.407 & 0.427 & $15.6 \%$ \\
\hline An31006 & $(\mathrm{AAAC}) 6$ & $\begin{array}{l}\text { Fwd: TTAAGAGCACCCTAGTACGGC } \\
\text { Rev: AGGACGTGTGGTAGTCATAGC }\end{array}$ & 29 & 3 & $325-333$ & 0.517 & 0.482 & $9.4 \%$ \\
\hline An31349 & $(\mathrm{AAAC}) 6$ & $\begin{array}{l}\text { Fwd: TGTGGCCAGCATTATTGACAC } \\
\text { Rev: AATTGCCCACAGTACAGCATG }\end{array}$ & 27 & 3 & $379-387$ & 0.259 & 0.338 & $15.6 \%$ \\
\hline An31977 & $(\mathrm{AACC}) 7$ & $\begin{array}{l}\text { Fwd: GCAGATAAGGAGGAAGGAACAC } \\
\text { Rev: CGGCATTACTGAGATACAAGCC }\end{array}$ & 26 & 2 & $315-319$ & 0.040 & 0.040 & $21.9 \%$ \\
\hline An40639 & $(\mathrm{ACAT}) 7$ & $\begin{array}{l}\text { Fwd: ATTATCCCTCAACCTGCCCTC } \\
\text { Rev: GTGGAGAATGTCAAGCCCATG }\end{array}$ & 28 & 5 & $195-211$ & 0.581 & 0.651 & $12.5 \%$ \\
\hline An50077 & $(\mathrm{AAGC}) 7$ & $\begin{array}{l}\text { Fwd: CACATTCCACTCCTTGCTCTG } \\
\text { Rev: AGTGGGATGAGCGTTGTCTTC }\end{array}$ & 31 & 2 & 189-193 & 0.065 & 0.064 & $3.1 \%$ \\
\hline An82902 & $(\mathrm{AGGG}) 6$ & $\begin{array}{l}\text { Fwd: TACGGTACCAGAATCTTGCCC } \\
\text { Rev: AACTCAATGTGACAGTTGGCC }\end{array}$ & 27 & 3 & $208-216$ & 0.259 & 0.289 & $15.6 \%$ \\
\hline An108380 & $(\mathrm{AGAT}) 15$ & $\begin{array}{l}\text { Fwd: CTCCAGTGTTTGCTAGTTGGC } \\
\text { Rev: CTAACACTAACACCCGAAAGCC }\end{array}$ & 23 & 6 & $166-194$ & 0.69565 & 0.78357 & $28.1 \%$ \\
\hline
\end{tabular}

Table 2. List of forward (Fwd) and reverse (Rev) primers for 24 newly established microsatellite markers for Accipiter nisus. Repeat counts are from the initial library; numbers and length ranges of alleles, as well as percent of missing data, refer to the entire set of 32 samples. Length range (inferred bp) include primers and linker. NA, not applicable; \# monomorphic marker, excluded from descriptive statistics and analyses; \#\# marker with either excessive amount of missing data or significant deviation from Hardy-Weinberg equilibrium (marked with an asterisk), excluded from some analyses. HO, observed heterozygosity; HE, expected heterozygosity. 
of all five subspecies included in the analysis, and differed by one mutational step each from the four other haplotypes: two singleton haplotypes containing one sample of $A$. nisus nisosimilis and one sample of unknown subspecies attribution; one haplotype representing three samples of $A$. nisus nisus; and one haplotype representing samples of A. nisus nisus and $A$. nisus nisosimilis. The island samples from Madeira, Tenerife and Sardinia ( $A$. nisus granti, $A$. nisus wolterstorffi) did not show any sequence difference.

\section{DISCUSSION}

The primary goal of this study was mainly to establish novel markers, not to perform a thorough analysis of range-wide variation in the Eurasian Sparrowhawk which would have required a much larger number of samples and more geographic sampling. For instance, analyses such as STRUCTURE often perform poorly with data sets characterized by few samples and uneven distribution of samples across putative genetic populations. De-

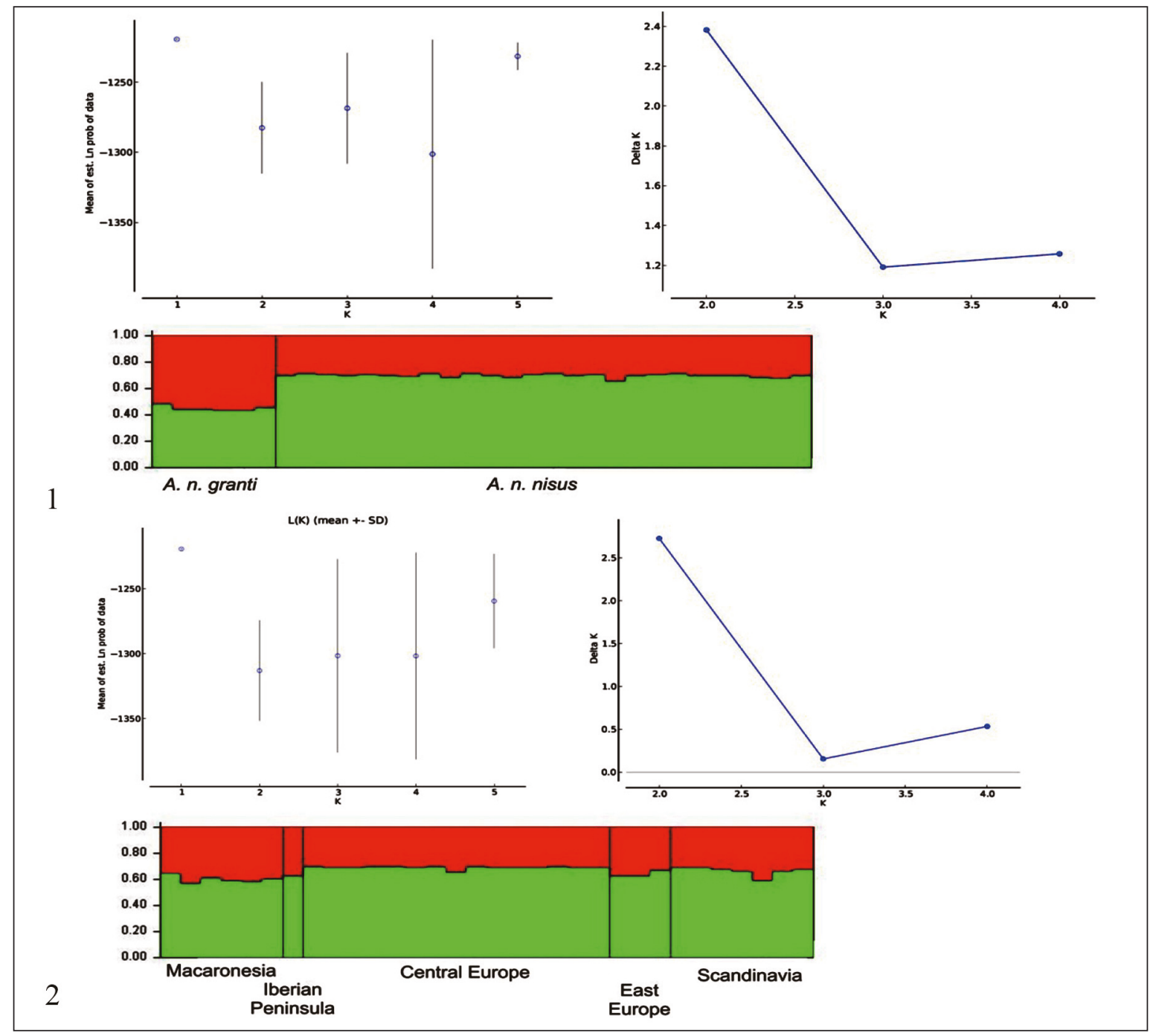

Figures 1, 2. Results of analyses with STRUCTURE of the full dataset of 22 polymorphic microsatellites for 32 samples of the Eurasian Sparrowhawk, Accipiter nisus. Each panel shows a graph with likelihood values for runs with different numbers of assumed clusters ( $\mathrm{K}=1$ to 5$)$, a second graph with delta-K values, and an exemplary plot of cluster membership for all individuals for $\mathrm{K}=2$. Fig. 1 shows analyses in which subspecies assignment was used as locprior (Macaronesia vs. Europe), whereas in Fig. 2, samples from continental Europe were divided into several ad-hoc geographical groups and these used as locprior. 
spite these restrictions, it is worth reporting that mitochondrial DNA sequences and microsatellites both failed to indicate a relevant genetic differentiation of any geographical group or subspecies included in the respective data set. Only in the Macaronesian subspecies A. nisus granti did the microsatellite data indicate a possible, very weak differentiation that requires confirmation from future study with more comprehensive sampling. Because these birds are partial migrants, it cannot be excluded that a purely resident part of the Macarone- sian subspecies may be genetically distinct but was not sampled for this study - although we consider this an unlikely hypothesis. For the North African subspecies A. nisus punicus, only a short coxl sequence was available from the study of Breman et al. (2013), but for this short stretch of the gene it does not show differences to the other subspecies, making a strong genetic divergence of this subspecies unlikely. For this and the remaining subspecies included in this study, only mtDNA information (i.e., coxl sequences) was available and

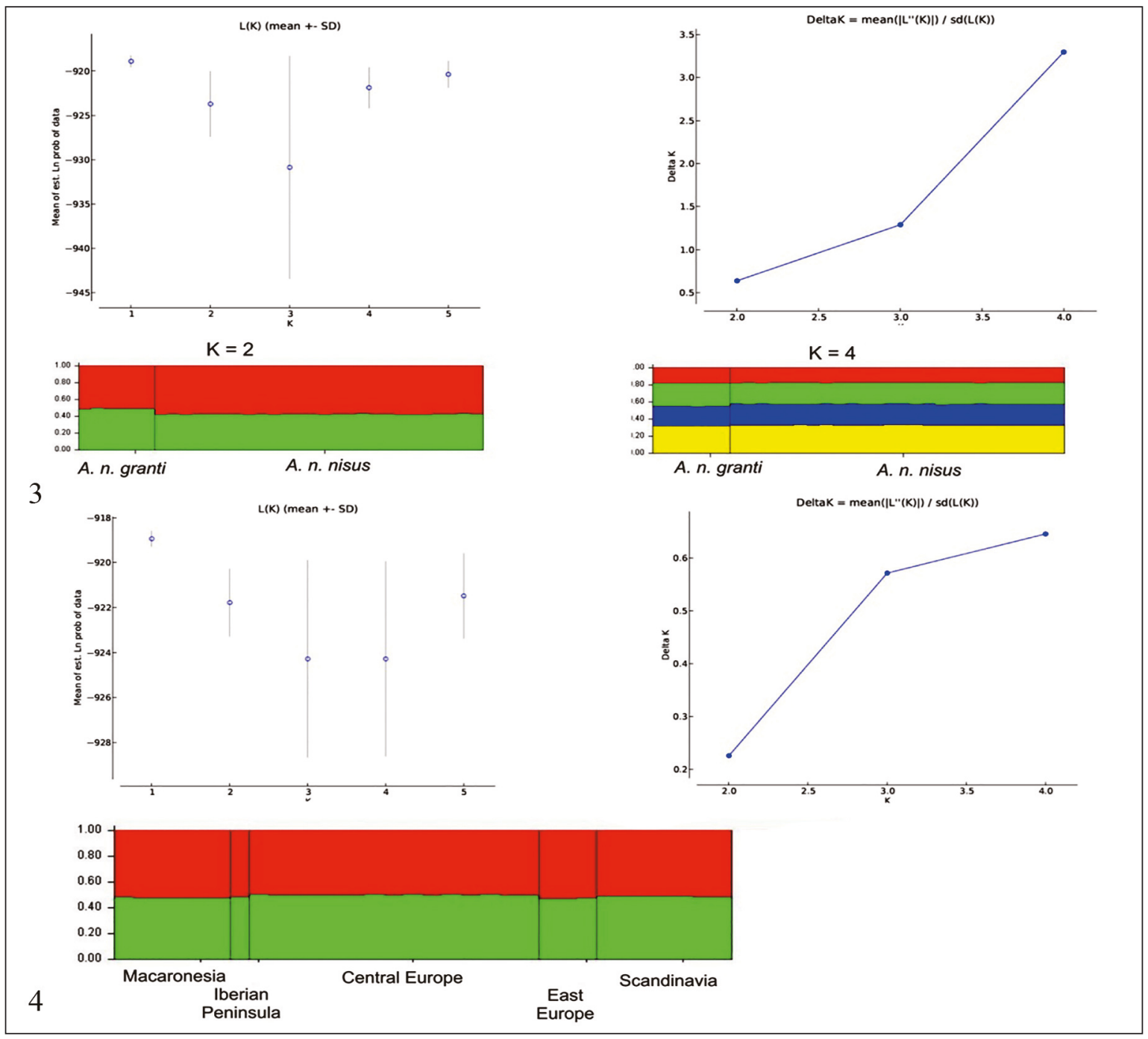

Figures 3, 4. Results of analyses with STRUCTURE of the reduced dataset of 16 polymorphic microsatellites for 32 samples of the Eurasian Sparrowhawk, Accipiter nisus, after excluding 6 markers with either excessive amounts of missing data or lack of Hardy-Weinberg equilibrium. Each panel shows a graph with likelihood values for runs with different numbers of assumed clusters $(\mathrm{K}=1$ to 5 ), a second graph with delta-K values, and an exemplary plot of cluster membership for all individuals for $\mathrm{K}=2$ (and $\mathrm{K}=4$ in Fig. 3). Fig. 3 shows analyses in which subspecies assignment was used as locprior (Macaronesia vs. Europe), whereas in Fig. 4, samples from continental Europe were divided into several ad-hoc geographical groups and these used as locprior. 
revealed a negligible amount of divergence; however, it is well-known that the purely maternally inherited, not recombining mtDNA can be affected by introgression phenomena, especially in cases of sex-biased dispersal, and therefore it will be worth testing in future studies whether especially the eastern subspecies (A. nisus nisosimilis, A. nisus melaschistos) may be divergent in their nuclear genome.

Although our study covers only a limited selection of samples, our preliminary study allows to draw the hypothesis that the Eurasian Sparrowhawk is characterized by only limited genetic variation across its range, in agreement with the pattern in numerous other raptors (e.g., Scheider et al. 2004; Sonsthagen et al., 2004). Many Eurasian bird taxa show such patterns of panmixia, probably reflecting that during the last 2 million years most parts of Eurasia have undergone a regular change from warm and cold period (ice ages), the last one ending only 12000 years ago. During ice ages, most Eurasia bird taxa had to move to refuge areas in southern

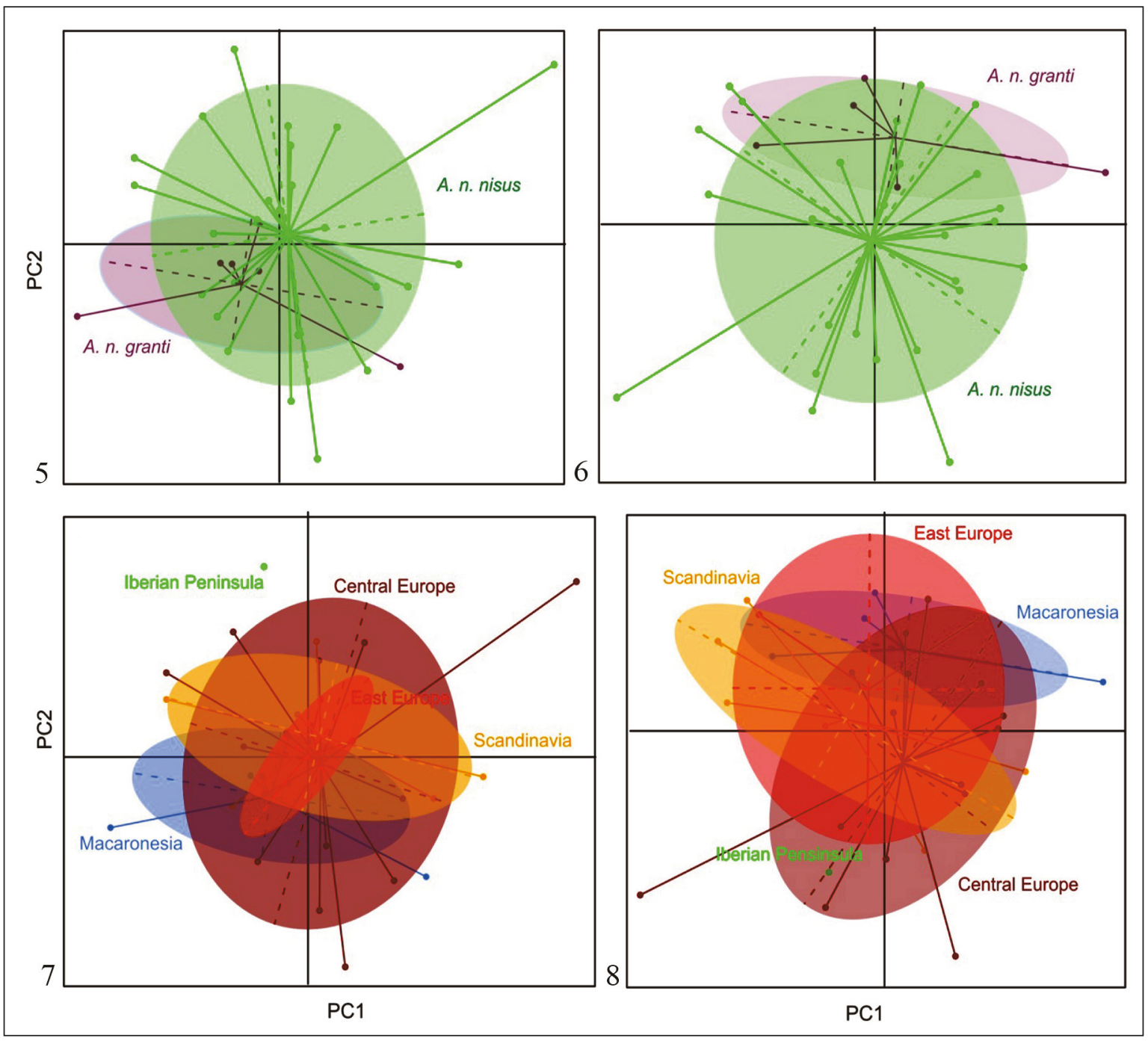

Figures 5-8. Results of Principal Component Analyses (first and second axis, respectively) from microsatellite data for the Eurasian Sparrowhawk, Accipiter nisus. Panels A and C show the results of a PCA based on all 22 polymorphic microsatellites; Figs. 7, 8. show results from a reduced set of 16 markers, after excluding markers with excessive missing data and deviation from Hardy-Weinberg equilibrium. In Fig. 5 and Fig. 6, samples are color-coded according to currently accepted subspecies assignment, in Fig. 7 and Fig. 8, additionally, samples of A. n. nisus from Europe are color-coded according to ad-hoc geographical groups. PC1 and PC2 are the two first principal components. 


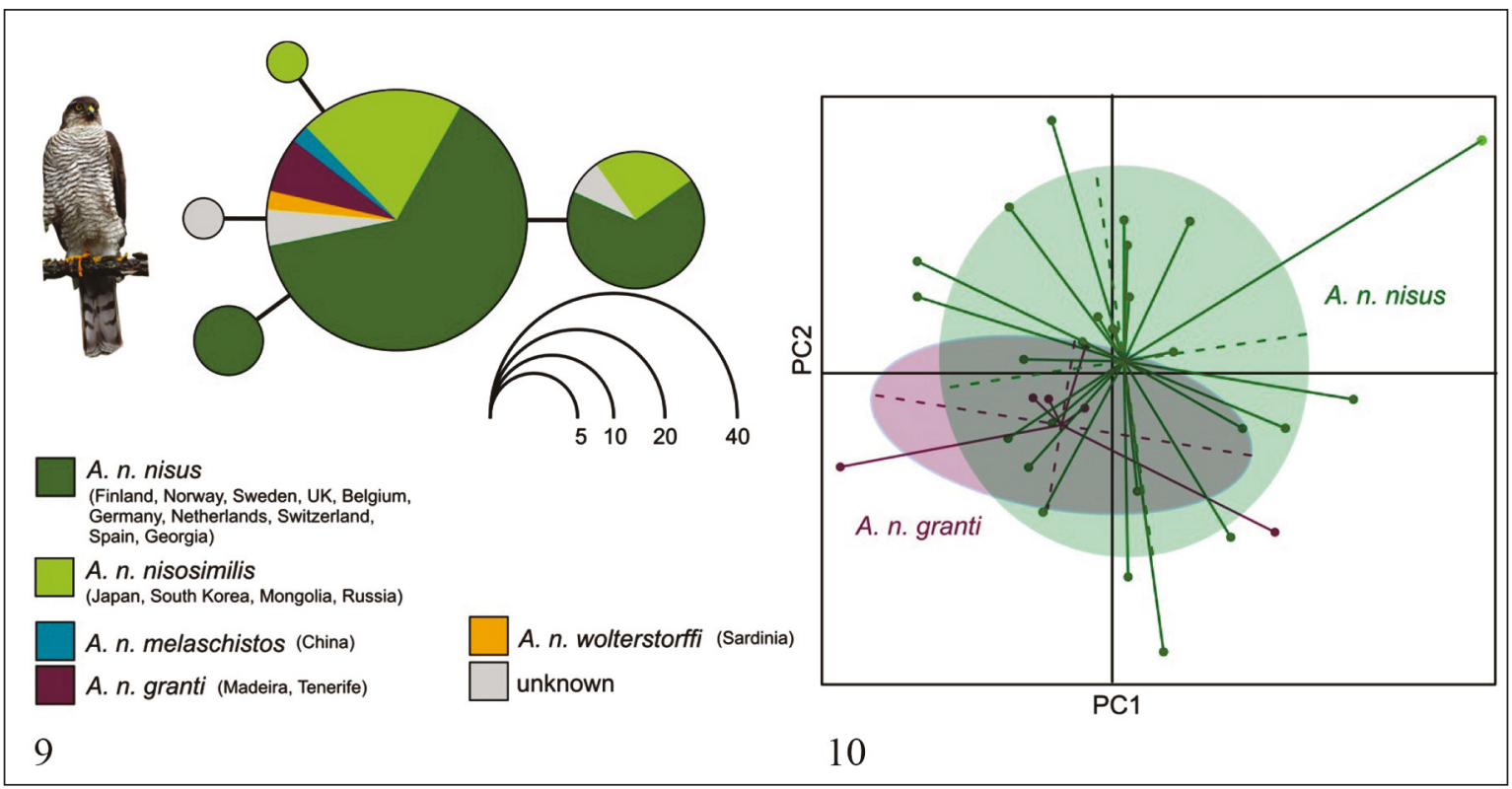

Figures 9, 10. Molecular evidence for low molecular differentiation among populations of the Eurasian Sparrowhawk (Accipiter nisus). Fig. 9: haplotype network based on $586 \mathrm{bp}$ of the mitochondrial coxl gene for 63 samples from across the species' range. Fig. 10: Principal Component Analysis based on 22 microsatellite markers for 32 samples, showing very low divergence among A. n. nisus from various parts of Europe, and A. $n$. granti from the Macaronesian islands, Tenerife and Madeira (recolored version of Fig. 5). Assignment of samples to subspecies in both panels is based on their geographical occurrence. PC1 and PC2 are the two first principal components (explaining 9.3\% and 8.8\%. of the variation).

Europe, Africa or southern Asia, where lineages mixed. Even if a genetic differentiation existed before, it was probably lost during the times in refuge areas (Wang et al., 2017; Carneiro et al., 2019; Parau et al., 2019).

Besides phylogeography, the newly developed microsatellites presented here provide a genomic resource for future conservation genetics, conservation breeding, individual recognition and paternity analysis of Eurasian Sparrowhawks.

\section{ACKNOWLEDGMENTS}

We are grateful to Steven M. Bogdanowicz (Cornell University) for his reliable service in microsatellite library development, Meike Kondermann and Gabriele Keunecke for assistance during laboratory work, Robin Schmidt for his help with microsatellite scoring and statistical analysis, and Heinz Brüning (Dülmen), Vera Deerques, Guillermo Delgado Castro (Centro de Rehabilitacion de Fauna Silvestre, La Laguna, Tenerife), Jukka Haapala (Finnish Museum of Natural History), Stefan C. Hügel (Tromsö Museum), Steve Petty (Forestry
Commission, Research Division, Argyll), Wulf Rheinwald, Dietrich Ristow, Ulrich Schneppat (Bündner Natur Museum, Chur), Hans-Hinrich Witt who collected samples used in this study, or made them available via their respective institutions.

\section{REFERENCES}

Aliabadian M., Beentjes K.K., Roselaar C.S.K., van Brandwijk H., Nijman V. \& Vonk R., 2013. DNA barcoding of Dutch birds. ZooKeys, 365: 25-48. https://doi.org/10.3897/zookeys.365.6287

BirdLife International. 2016. Accipiter nisus. The IUCN Red List of Threatened Species 2016: e.T22695624A93519953. https://dx.doi.org/10. 2305/IUCN.UK.2016-3.RLTS.T22695624 A93519953.en. Downloaded on 28 October 2020.

Breman F.C., Jordaens K., Sonet G., Nagy Z.T., Van Houdt J. \& Louette M., 2013. DNA barcoding and evolutionary relationships in Accipiter Brisson, 1760 (Aves, Falconiformes: Accipitridae) with a focus on African and Eurasian representatives. Journal of Ornithology, 154: 265-287.

Brune J., Krüger O., Hippauf E., Rösner S. \& Katzenberger J., 2019. Eine nichtinvasive Methode für Popu- 
lationsstudien beim Rotmilan Milvus milvus: Molekulargenetische Individualerkennung anhand von Mauserfedern. Vogelwelt, 139: 129-140.

Cai Y., Yue B., Jiang W., Xie S., Li J. \& Zhou M., 2010. DNA barcoding on subsets of three families in Aves. Mitochondrial DNA, 21: 132-137. https://doi.org/10.3109/19401736.2010.494726

Carneiro de Mela Moura C., Bastian H.-V., Bastian A., Wang E., Wang, X. \& Wink M., 2019. Pliocene origin, ice ages and postglacial population expansion have influenced a panmictic phylogeography of the European bee-eater Merops apiaster. Diversity, 11: 12. https://doi.org/10.3390/d11010012

Earl D.A. \& Von Holdt B.M., 2012. STRUCTURE HARVESTER: A website and program for visualizing STRUCTURE output and implementing the Evanno method. Conservation Genetics Resources, 4: 359361. https://doi.org/10.1007/s12686-011-9548-7

Evanno G., Regnaut S. \& Goudet J., 2005. Detecting the number of clusters of individuals using the software STRUCTURE: A simulation study. Molecular Ecology, 14: 2611-2620.

https://doi.org/10.1111/j.1365-294X.2005.02553.x

Excoffier L., Laval G. \& Schneider S., 2005. Arlequin (version 3.0): An integrated software package for population genetics data analysis. Evolutionary Bioinformatics, 1: 47-49. https://doi.org/10.1177/117693430500100003

Excoffier L. \& Lischer H.E.L., 2010. Arlequin suite ver 3.5: A new series of programs to perform population genetics analyses under Linux and Windows. Molecular Ecology Resources, 10: 564-567 https://doi.org/10.1111/j.1755-0998.2010.02847.x

Ferguson-Lees J., 2009. Die Greifvögel der Welt: 338 Arten, uber 2100 Farbzeichnungen. Kosmos, Stuttgart.

Gill F., Donsker D. \& Rasmussen, P. , 2020, Eds. IOC World Bird List (v10.1). https://doi.org/10.14344/IOC.ML.10.1.

Guo S.W. \& Thompson E.A., 1992. Performing the exact tTest of Hardy-Weinberg proportion for multiple alleles. Biometrics, 48: 361-72. JSTOR 48: 361. https://doi.org/10.2307/2532296

Hailer F., Gautschi B. \& Helander B., 2005. Development and multiplex PCR amplification of novel microsatellite markers in the White-tailed Sea Eagle, Haliaeetus albicilla (Aves: Falconiformes, Accipitridae). Molecular Ecology Notes, 5: 938-940. https://doi.org/10.1111/j.1471-8286.2005.01122.x

Hebert P.D.N., Ratnasingham S. \& DeWaard J.R., 2003. Barcoding animal life: cytochrome c oxidase subunit 1 divergences among closely related species. Proceedings of the Royal Society B: Biological Sciences, 270: 96-99. https://doi.org/10.1098/rsbl.2003.0025

Hubisz M.J., Falush D., Stephens M. \& Pritchard J.K., 2009. Inferring weak population structure with the assistance of sample group information. Molecular Ecology Resources, 9: 1322-1332. https://doi.org/10.1111/j.1755-0998.2009.02591.x. Johnson A., Rindal E., Ericson P.G.R., Zuccon D., Kerr K.C.R., Stoeckle M.Y. \& Lifjeld J.T., 2010. DNA barcoding of Scandinavian birds reveals divergent lineages in trans-Atlantic species. Journal of Ornithology, 151: 565-578.

Johnson J.A., Watson R.T. \& Mindell D.P., 2005. Prioritizing species conservation: does the Cape Verde kite exist? Proceedings of the Royal Society B: Biological Sciences, 272: 1365-1371. https://doi.org/10.1098/rspb.2005.3098

Jombart T., 2008. adegenet: a R package for the multivariate analysis of genetic markers. Bioinformatics, 24: $1403-1405$. https://doi.org/10.1093/bioinformatics/btn129

Jombart T., Pontier D. \& Dufour A.-B., 2009. Genetic markers in the playground of multivariate analysis. Heredity, 102: 330-341.

Keenan K., McGinnity P., Cross T.F., Crozier W.W. \& Prodöhl P.A., 2013. diveRsity: An R package for the estimation and exploration of population genetics parameters and their associated errors. Methods in Ecology and Evolution, 4: 782-788. https://doi.org/10.1111/2041-210X.12067

Kerr K.C.R., Birks S.M., Kalyakin M.V., Red'Kin Y.A., Koblik E.A. \& Hebert P.D., 2009. Filling the gap COI barcode resolution in eastern Palearctic birds. Frontiers in Zoology, 6: 29. https://doi.org/10.1186/1742-9994-6-29.

Kretzmann M.B., Capote N., Gautschi B., Godoy J.A., Donázar J.A. \& Negro J.J., 2003. Genetically distinct island populations of the Egyptian vulture (Neophron percnopterus). Conservation Genetics, 4: 697-706. https://doi.org/10.1023/B: COGE.0000006123.67128.86.

Kruckenhauser L., Haring E., Pinsker W., Riesing M.J., Winkler H., Wink M. \& Gamauf A., 2004. Genetic vs. morphological differentiation of Old World buzzards (genus Buteo, Accipitridae). Zoologica Scripta, 33: 197-211. https://doi.org/10.1111/j.0300-3256.2004.00147.x.

Kumar S., Stecher G. \& Tamura K., 2016. MEGA7: Molecular Evolutionary Genetics Analysis Version 7.0 for Bigger Datasets. Molecular Biology and Evolution, 33: 1870-1874. https://doi.org/10.1093/molbev/msw054

Margaryan A., 2019. Unpublished sequence submitted within the DNAmark (A Danish DNA Reference Database) project (https://dnamark.ku.dk).

Mebs T., 2002. Greifvögel Europas - Biologie, Bestandsverhältnisse, Bestandsgefährdung. Kosmos, Stuttgart.

Meyer C., Geller J. \& Paulay G., 2005. Fine scale endemism on coral reefs: Archipelagic differentiation in turbinid gastropods. Evolution, 59: 113-125. 
Nazareno A.G. \& Reis M.S.D., 2011. The same but different: monomorphic microsatellite markers as a new tool for genetic analysis. American Journal of Botany, 98: 265-267. https://doi.org/10.3732/ajb.1100163

Pârâu L., Frias-Soler R. \& Wink M., 2019. High genetic diversity among breeding red-backed Shrikes Lanius collurio in the Western Palearctic. Diversity, 11: 31. https://doi.org/10.3390/d11030031

Perl R.G.B., Geffen E., Malka Y., Barocas A., Renan S., Vences M. \& Gafny S., 2018. Population genetic analysis of the recently rediscovered Hula painted frog (Latonia nigriventer) reveals high genetic diversity and low inbreeding. Scientific Reports, 8: 111. https://doi.org/10.1038/s41598-018-23587-w.

Pritchard J.K., Stephens M. \& Donnelly P., 2000. Inference of population structure using multilocus genotype data. Genetics, 155: 945-959.

R Core Team, 2020. R: A language and environment for statistical computing. R Foundation for Statistical Computing, Vienna, Austria. URL http://www.R-project.org/

Saitoh T., Sugita N., Someya S., Iwami Y., Kobayashi S., Kamigaichi H., Higuchi A., Asai S., Yamamoto Y. \& Nishiumi I., 2015. DNA barcoding reveals 24 distinct lineages as cryptic bird species candidates in and around the Japanese Archipelago. Molecular Ecology Resources, 15: 177-186. https://doi.org/10.1111/1755-0998.12282.

Salzburger W., Ewing G.B. \& Von Haeseler A., 2011. The performance of phylogenetic algorithms in estimating haplotype genealogies with migration. Molecular Ecology, 20: 1952-1963. https://doi.org/10.1111/j.1365-294X.2011.05066.x

Scheider J., Wink M., Stubbe M., Hille S. \& Witschko
W., 2004. Phylogeographic relationships of the Black Kite Milvus migrans. In: Chancellor R.D., Meyburg B.U. (Eds.) Raptors Worldwide, WWGBP/MME, Budapest, pp. 467-472.

Schuelke M., 2000. An economic method for the fluorescent labeling of PCR fragments. Nature Biotechnology, 18: 233.

Sonsthagen S.A., Talbot S.L. \& White C.M., 2004. Gene flow and genetic characterization of Northern Goshawks breeding in Utah. The Condor, 106: 826. https://doi.org/10.1650/7448.

Topinka J.R. \& May B. 2004. Development of polymorphic microsatellite loci in the northern goshawk ( $A c$ cipiter gentilis) and cross-amplification in other raptor species. Conservation Genetics, 5: 861-864.

Wang E., Wijk R.E.V., Braun M.S. \& Wink M., 2017. Gene flow and genetic drift contribute to high genetic diversity with low phylogeographical structure in European hoopoes (Upupa epops). Molecular Phylogenetics and Evolution, 113: 113-125. https://doi.org/10.1016/j.ympev.2017.05.018

Ward R.D., Zemlak T.S., Innes B.H., Last P.R. \& Hebert P.D.N., 2005. DNA barcoding Australia's fish species. Philosophical Transactions of the Royal Society London B, 360: 1847-1857.

Yoo H.S., Eah J.Y., Kim J.S., Kim Y.J., Min M.S., Paek W.K., Lee H. \& Kim C.B., 2006. DNA barcoding Korean birds. Molecules and Cells, 22: 323-327 [manuscript retracted due to plagiarism but DNA sequences available in GenBank]

Zhang H., Dou H., Yang X., Zhao C., Liu G. \& Zhang J., 2014. The complete mitrochondrial genome sequence of the sparrowhawk (Accipiter nisus). Mitochondrial DNA A DNA, 27: 1648-1649. https://doi.org/10.3109/19401736.2014.958711 